\title{
Brain-Derived Neurotrophic Factor Is More Highly Conserved in Structure and Function than Nerve Growth Factor During Vertebrate Evolution
}

\author{
Rudolf Götz, Friedrich Raulf, and Manfred Schartl \\ Genecenter, Max-Planck-Institute for Biochemistry, Planegg-Martinsried, F.R.G.
}

\begin{abstract}
Mammalian nerve growth factor (NGF) and brain-derived neurotrophic factor (BDNF) are members of a protein family with perfectly conserved domains arranged around the cysteine residues thought to stabilize an invariant three-dimensional scaffold in addition to distinct sequence motifs that convey different neuronal functions. To study their structural and functional conservation during evolution, we have compared NGF and BDNF from a lower vertebrate, the teleost fish Xiphophorus, with the mammalian homlogues. Genomic clones encoding fish NGF and BDNF were isolated by cross-hybridization using probes from the cloned mammalian factors. Fish NGF and BDNF were expressed by means of recombinant vaccinia viruses, purified, and their neuronal survival specificities for different classes of neurons were found to mirror those of the mammalian factors. The half-maximal survival concentration for chick sensory neurons was $60 \mathrm{pg} / \mathrm{ml}$ for both fish and mammalian purified recombinant BDNF. However, the activity of recombinant fish NGF on both chick sensory
\end{abstract}

and sympathetic neurons was $6 \mathrm{ng} / \mathrm{ml}, 75$-fold lower than that of mouse NGF. The different functional conservation of NGF and BDNF is also reflected in their structures. The DNA-deduced amino acid sequences of processed mature fish NGF and BDNF showed, compared to mouse, $63 \%$ and $90 \%$ identity, respectively, indicating that NGF bad reached an optimized structure later than BDNF. The retrograde extrapolation of these data indicates that NGF and BDNF evolved at strikingly different rates from a common ancestral gene about 600 million years ago. By RNA gel blot analysis NGF mRNA was detected during late embryonic development; BDNF was present in adult brain. Key Words: Brain-derived neurotrophic factor-Nerve growth factor-Fish-Recombinant protein expression-Neuronal survival. Götz R. et al. Brain-derived neurotrophic factor is more highly conserved in structure and function than nerve growth factor during vertebrate evolution. J. Neurochem. 59, 432-442 (1992).
The basic building blocks of the nervous system, the neurons, show remarkable morphological and functional similarities throughout the animal phyla. However, the regulatory mechanisms involved in the development of the nervous systems at different evolutionary levels show different characteristics. In invertebrates, the development of the nervous system is generally subjected to a rigid, genetically determined pattern of cell lineage (e.g., Sulston and Horvitz, 1977; Truman and Schwartz, 1982). In contrast, the development of the nervous system of vertebrates, particularly higher vertebrates, depends extensively on epigenetic mechanisms, i.e., interactions of neurons with other neurons and with nonneuronal cells (Ja- cobson, 1991). It is a general principle that in vertebrates, in the early stages of ontogeny a surplus of neurons is produced and after the arrival of their axons in the target areas, the final number of neurons is determined by regulated, regionally different neuronal cell death. The extent of neuronal death can be increased experimentally by removing the corresponding target tissues; conversely, grafting extra target tissue allows more neurons to survive (reviewed by Cowan et al., 1984). Neurotrophic factors produced by these neuronal and nonneuronal target cells are the molecular mediators that regulate the extent of neuronal survival and determine the density of innervation (reviewed by Barde, 1989).
Received September 11, 1991; revised manuscript received January 8, 1992; accepted January 14, 1992.

Address correspondence and reprint requests to Dr. R. Götz at Max-Planck-Institut for Psychiatry, Am Klopferspitz 18a, D-8033 Martinsried, F.R.G.

The present address of Dr. M. Schartl is Biocenter, Department of Physiological Chemistry I, University Würzburg, Am Hubland, D-8700 Würzburg. F.R.G.

Abbreviations used: BDNF, brain-derived neurotrophic factor; NGF, nerve growth factor; PBS, phosphate-buffered saline; SDSPAGE, sodium dodecyl sulfate-polyacrylamide gel electrophoresis. 
The best characterized neurotrophic molecule is nerve growth factor (NGF). It plays an important role in the regulation of the survival, differentiation, and maintenance of specific functions of the peripheral sympathetic nervous system and subpopulations of sensory neural crest-derived neurons (reviewed by Levi-Montalcini, 1987). More recently, NGF has also been demonstrated to support subpopulations of neurons in the CNS, in particular cholinergic neurons of the basal forebrain nuclei (reviewed by Thoenen et al., 1987; Whittemore and Seiger, 1987). The recent cloning of brain-derived neurotrophic factor (BDNF) (Leibrock et al., 1989), neurotrophin-3 (Hohn et al., 1990; Maisonpierre et al., 1990; Rosenthal et al., 1990; Ernfors et al., 1990; Kaisho et al., 1990; Jones and Reichardt, 1990), and neurotrophin-4 (Hallböök et al., 1991) revealed the existence of additional neurotrophic factors that are structurally related to NGF, and yet show, as far as established, distinctly different neuronal specificities and different patterns of regional distribution, cellular localization, and developmental expression (reviewed by Barde, 1989; Thoenen, 1991). So far the comparative information on the different members of the NGF gene family has been restricted to higher vertebrates. Recently, partial sequences (encoding $\sim 42$ amino acid residues) of neurotrophins of lower vertebrates have been determined (Hallböök et al., 1991). The comparative structure-function analysis of neurotrophic factors of lower vertebrates and mammals can be expected to reveal important new information provided such an analysis is performed in quantitative assay systems and with purified proteins. Moreover, the evolutionary analysis should provide information as to whether and when the different members of the gene family originated from a common ancestor.

As a first step toward this goal we investigated an organism at the stem of the vertebrate branch of the phylogenetic tree. Fish represent one of the oldest vertebrate groups. They diverged approximately $450 \mathrm{mil}-$ lion years ago from the vertebrate stem. We have chosen the fish Xiphophorus to study the presence, biological significance, and evolutionary origin of NGF and BDNF. This small teleost species is currently one of the best characterized fish genetically and molecularly and, in addition, is easy to grow (reviewed by Adam et al., 1990).

We report here the cloning of NGF and BDNF from the platyfish Xiphophorus maculatus and the production and biological characterization of recombinant fish NGF and BDNF. The production and purification of recombinant fish NGF and BDNF permitted the determination of their neuronal survival specificities and their specific activities. In agreement with the highly conserved structure $(90 \%$ amino acid identity) the biological activity of fish BDNF was identical to that of mammalian BDNF. In contrast, the specific activity of fish NGF analyzed in chick sensory and sympathetic neurons is considerably lower than that of mouse NGF. This was reflected by a much lower $(63 \%)$ structural conservation.

\section{MATERIALS AND METHODS}

\section{Cloning of NGF and BDNF}

A genomic library that had been prepared by inserting DNA from Xiphophorus maculatus (origin Rio Usumacinta, Mexico) partially digested with Sau3A into the BamHI cloning site of the bacteriophage vector EMBL4 (Frischauf et al., 1983) was screened (Benton and Davis, 1977) under reduced stringency conditions with radioactively labeled DNA fragments corresponding to mature pig BDNF (Leibrock et al., 1989). The probe was labeled with $\left[\alpha{ }^{32}\right.$ P]dCTP as described by Rigby et al. (1977) and Feinberg and Vogelstein (1983). The conditions for hybridization had been established on Southern blots (Southern, 1975) of genomic fish DNA and were $5 \times$ SSC $(1 \times$ SSC is $0.15 M \mathrm{NaCl}, 0.015 \mathrm{M}$ sodium citrate, $\mathrm{pH} 7.2$ ), $40 \%$ formamide at $42^{\circ} \mathrm{C}$ with washes in $2 \times \mathrm{SSC}$ at $60^{\circ} \mathrm{C}$. Clones were plaque purified and their DNA prepared and mapped with restriction endonucleases according to standard protocols (Maniatis et al., 1982). The 1.8- and 1.3-kbp EcoRI fragments hybridizing with the BDNF probe were subcloned into pUC 13 and M $13 \mathrm{mp} 18$ vectors (Norrander et al., 1983) for further analysis.

To clone the fish NGF, genomic DNA fragments in the size range $2.6-3.3 \mathrm{kbp}$ separated by agarose gel electrophoresis were purified (Vogelstein and Gillespie, 1979), ligated into the vector $\lambda$ gt 10 (Huynh et al., 1985), and packaged into phage particles as specified by the manufacturer of the packaging kit (Amersham). A positive clone (A5.2) was isolated as described above and its insert was subcloned into the plasmid vector pT7T3 18U (Pharmacia).

\section{DNA sequencing}

DNA sequencing was done on both strands according to the chain termination method (Sanger et al., 1977) with ${ }^{35} \mathrm{~S}-\mathrm{dATP}$ and T7 DNA polymerase using the instructions of the supplier of the enzyme (Pharmacia). We used both double- and single-stranded templates that had been constructed by subcloning appropriate restriction fragments and by generating nested deletions with exonuclease III as described by Henikoff (1984). As primers M13 universal primer, M13 reverse primer, and insert-specific primers were employed. Oligonucleotides were synthesized by an Applied Biosystems automated DNA synthesizer. The sequences were analyzed with the UWGCG programs (Devereux et al., 1984).

\section{Expression of neurotrophic factors}

Two recombination plasmids were constructed that contained the fish NGF or BDNF coding sequences. For NGF expression, a 1,087-bp HindIII-DraI fragment (see Fig. 1) was inserted into the vector $11 \mathrm{kd} 6-131$ linearized with HindIII and EcoRV. To express BDNF, the 1,304-bp EcoRI fragment encoding BDNF in the $\lambda$ phage clone B 14 (see Fig. 1) was cloned in the correct orientation for protein expression into the vector $1 \mathrm{lk}$-Ata 18 (Stunnenberg et al., 1988). The vector $11 \mathrm{kd} 6-131$ is similar to $11 \mathrm{k}$-Ata 18 except for the polylinker. Vaccinia recombinant virus was generated by transfection with plasmid DNA of human TK $^{-} 143$ cells (Rhim et al., 1975) infected with wild-type virus (strain WR) and subsequent selection of TK ${ }^{-}$virus as described by Mackett et al. (1984). Recombinant virus was differentiated 
from spontaneous $\mathrm{TK}^{-}$virus by polymerase chain reaction assays (Saiki et al., 1988) with oligonucleotide primers specific for the NGF or BDNF inserts. For protein production, rabbit kidney cells ( RK $_{13}$ cell line, ATCC number CCL 37) grown as monolayers in plastic culture flasks were infected with recombinant virus and after a 6-h growth period in Dulbecco's modified Eagle's medium containing 5\% fetal calf serum, medium was removed and cells were washed with phosphate-buffered saline (PBS). Serum-free medium was added and after incubation for 24-36 h, conditioned medium was harvested. After cells had been removed by centrifugation, the conditioned medium was pumped over a 4-ml (bed volume) controlled pore glass column essentially as described by Eichner et al. (1989); washed with 200 $\mathrm{ml} \mathrm{PBS}$; and eluted with $20 \mathrm{ml}$ of $50 \%$ acetonitrile, $100 \mathrm{mM}$ $\mathrm{NaCl}$, and $100 \mathrm{mM}$ acetic acid. Purification was achieved by reversed-phase HPLC (Aquapore RP-300 column, 2.1 $\times 22 \mathrm{~mm}$, Applied Biosystems). The purification was monitored by sodium dodecyl sulfate-polyacrylamide gel electrophoresis (SDS-PAGE) (Laemmli, 1970). Band intensities on gels were quantitated using an Ultrascan laser densitometer (Pharmacia-LKB Instruments) with known amounts of a lysozyme standard for calibration. Protein concentrations in conditioned medium were determined by the method of Bradford (1976). The neurotrophic activity was assayed according to the method of Lindsay et al. (1985).

\section{Northern (RNA) analysis}

RNA isolation following the $\mathrm{LiCl} / \mathrm{urea}$ procedure was performed as described previously by Mäueler et al. (1988). Twenty micrograms of total RNA was separated by electrophoresis on a $1.2 \%$ agarose gel in the presence of formaldehyde and then transferred to Hybond $\mathrm{N}$ nylon membranes
(Amersham). RNA standards (0.24- to 9.5-kb RNA ladder, $B R L$ ) were run in parallel for sizing. After UV fixation, the membrane-bound RNA was stained with methylene blue (Khandjian, 1986) for the exact quantitation of the amount of RNA transferred. Prehybridization and hybridization were performed as previously described by Mäueler et al. (1988) with final washes at $65^{\circ} \mathrm{C}$ in $0.1 \times$ SSC, $1 \%$ SDS. The 0.6-kbp SmaI-PstI fragment of the BDNF gene (see Fig. 1) was ${ }^{32} \mathrm{P}$ labeled with the random priming protocol (Feinberg and Vogelstein, 1983) and used as probe. The NGF antisense riboprobe (complementary to nucleotide positions 258-611; see Fig. 2) was transcribed from plasmid 1627 linearized with HindIII using T3 RNA polymerase following the protocol supplied by the manufacturer (Stratagene). Plasmid 1627 carries a 354-bp HindIII-Eco47III NGF subfragment ligated into the vector pT7T3-19 (Pharmacia) linearized with HindIII and Smal. For the removal of the probe, filters were incubated in $1 \%$ SDS at $80^{\circ} \mathrm{C}$ for $20 \mathrm{~min}$, and subjected to rehybridization after autoradiographic control.

\section{Nucleotide sequence accession number}

These sequence data are available from EMBL/GenBank/DDBJ under accession numbers X599.41 (fish NGF) and X59942 (fish BDNF).

\section{RESULTS}

\section{Cloning of fish NGF and BDNF}

Southern blots probed under low-stringency conditions with radioactively labeled fragments that corresponded to either mouse NGF (Scott et al., 1983) or

\section{A}
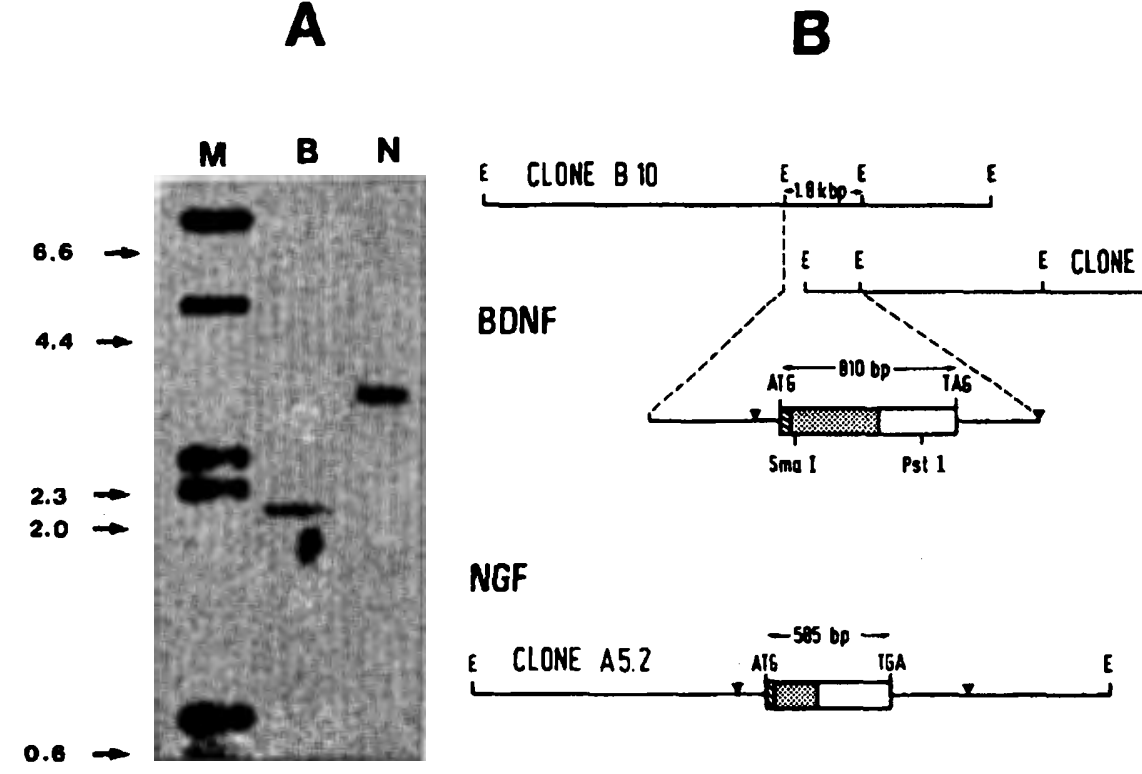

FIG. 1. Cloning of the NGF and BDNF genes of Xiphophorus. A: Detection of fish NGF and BDNF sequences in Southern blots of Xiphophorus DNA digested with EcoRI and probed under reduced stringency conditions (as specified in Materials and Methods) with mouse NGF (lane N) or pig BDNF (lane B). Size markers were ${ }^{32 P}$ labeled $\lambda$ HindlII fragments; the sizes are indicated in kbp (lane M). B: A map depicting the EcoRI (E) inserts of the BDNF and NGF clones is shown. For BDNF, an expanded representation of the genomic region whose sequence has been determined is given. Start codons, signal peptide regions (hatched segment), pro-regions (stippled box), mature regions (open box), and stop codons are indicated. The filled arrowheads mark the subfragments cloned for the expression of neurotrophic factors. 
pig BDNF (Leibrock et al., 1989) revealed a specific hybridizing band for each probe in the fish genome (Fig. 1A). Because the precursor proteins of NGF and BDNF of higher vertebrates are encoded in single exons (Ullrich et äl., 1983; Selby et al., 1987a; Leibrock et al., 1989) and because the intron/exon arrangements of homologous genes in fish and higher vertebrates have so far been found to be conserved (e.g., see Adam et al., 1991; Hannig et al., 1991), we isolated clones from genomic libraries. The $2.9-\mathrm{kbp}$ EcoRI fragment identified with the NGF probe in the
Southern blot was cloned from a size-selected genomic library (Fig. 1B). With the BDNF probe we identified a series of overlapping clones from a representative library that contained the hybridizing $1.8-\mathrm{kbp}$ EcoRI fragment (Fig. 1B).

\section{Strikingly different conservation of NGF and BDNF structures}

The identification of the isolated NGF gene is based on the following features: it encodes a protein with a molecular mass of $21.6 \mathrm{kDa}$ (194 amino acid resi-

\footnotetext{
N G F

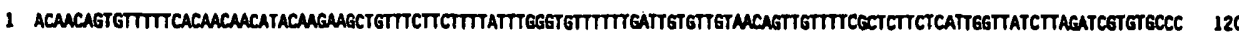
- Q L F SLFSLVILORVP

121 ATGAGGTCATCCATGCTEGTCCTGTTTCTCATCTTCATSCCCAGECTGTGGCCCCATCATAGGGGTCTTGSCAGCGTCACAACAGCACHCAGGACAACECCACCTCCATCCCCACT 240

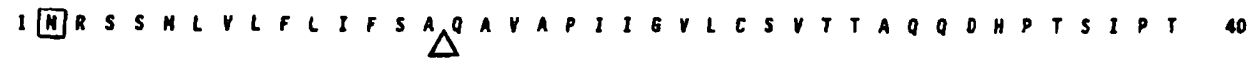

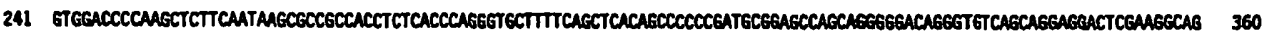
41 VDPLFNKRRHLSPRVLFSSPPPDAEPAG6OGVSRRTRRQ 80

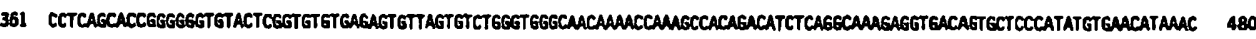

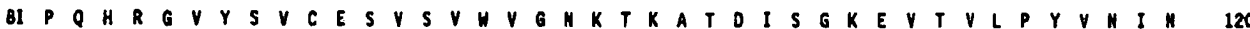

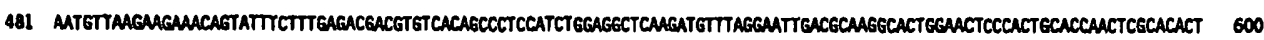
121 N VKKKQYFFETICHSPPSGGSRCLGI DARH NS HCTNSHT 160

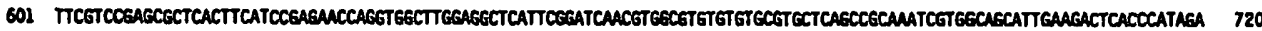
161 F VRALTSSENQVAWRLIRI WVACVCVLSRKSWQH -
}

\section{BDNF}

I ATTACGTGATGCATTARTGATCAGGAGGGGCTAGCTTTGGTAGAAATACTCTTTCACTAACCACCTTGTTCTCTTCCCTCTTTCTGTTCTCCCTCCAGTTCCACCAGGTTAGAGGAGT6 120 - C I N D Q E 6 A S F 6 R N TLSLTTLFSSLFLFSL OFHA

121 ATGACCATCCTGTTCCTTACTATGGTATTTCATACTTCAGTTGCATGAGAGCTGCGCCCCTGAGAGACGCCCCGGGCATGCGGGGCCATTGGACGGAGGCTACCTGGGCGCTGCTGCG 240

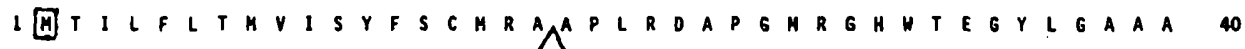
241 ACGGCCCCCCGAGGCCATGGGACTCCACAGAGTGGCGGCGGGCCGGGCCAGCGCGAGGAGCTCCCCTCGCTCACAGACACATTCGAGCAGGTGATAGAGGAGCTGCTGGAGTGGAGGGT 360 41 T A P R H G T P OS G 6 GPGQREELPSLTOTFEQVIEELLE VE G 80

361 GAGGCGGCGCACGTGGGACAGGGGGCCGACAAGAGTCAGGGAGGTGGGGCCCGTCGCCCGTGGCCACCGCAGAGGCCAATGATGTCGATCTGTACAACTCGCGGGTGATGATCAGCAAC 4BO

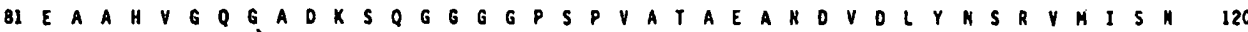
481 CAAGTGCCTTIGGAGCCGCCGTTGCTCTTTCTCCTGGAGGAATACAGAAACTATCTGGATGCTGCGAACATGTCCATGAGGGTGCGGCGGCACTCCGACCCCTCGCGGCGTGGAGAGCTC 600 121 O V P L E P P L L F L LE E Y K K Y L OA A N HS KR V RRA S OPS RR GEL L 601 AGTGTGTGTGACAGTATTAGCCAGTGGGTGACAGCTGTGGATAAAAGACEGCGATAGACATGTCTGGGCAGACAGTAACCGTCATGGAGMGGTCCCTGTCCCCAATGGCCAACTGAGG 720 161 S V C O S I S Q W V TA VOKKTAIOASG QTVTVHEKVPVPNGQLK 200

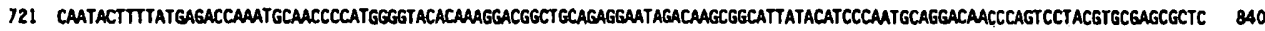
201 O Y F Y E T X-C N P H G Y T K O G CREI D X R H Y T S O CRT TOSYYRAL 240

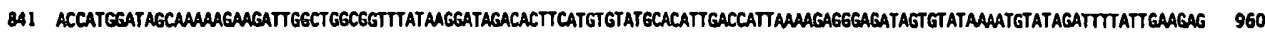
241 T H D S K X K I 6 H R F I R I O I S C V C T L T I K R 6 R *

FIG. 2. Fish NGF and BDNF gene and amino acid sequences. The open reading frame of the NGF and BDNF genes is shown; the starting methionine is boxed. Proteolytic cleavage to release the mature factor is marked with a filled arrowhead; these data are based on aminoterminal sequencing of the recombinant proteins (see Results). Predicted signal peptidase cleavage is indicated with an open arrowhead, potential sites for $\mathrm{N}$-linked glycosylation are underlined, and sequences with dibasic motifs are double underlined. 
dues), the carboxyl terminal 115 amino acids (the predicted mature form of fish NGF) displaying $63 \%$ identity to mature mouse NGF (Figs. 2 and 3; Table 1). The identification as fish NGF is based on the lower sequence identity to mouse BDNF (43\%) and mouse neurotrophin-3 (48\%) and was substantiated further by the activity of the recombinant protein (see below). Moreover, a different band hybridized in the Southern blot of fish DNA with the mouse NT-3 probe (data not shown). The initiating AUG is in accordance with empirical rules established for vertebrate mRNAs (Kozak, 1987). The N-terminal of the specified protein fulfills the characteristics of a signal peptide (Von Heijne, 1986). The pro-region of fish NGF shows a significant homology to the pro-segment of NGF from other species (e.g., $51 \%$ identity to the mouse sequence) but its length of 60 amino acids is considerably shorter than in other species (e.g., 103 amino acids in the mouse; for sequences see Schwarz et al., 1989). The predicted (and in recombinant molecules demonstrated) $\mathrm{N}$-terminal of the mature protein is located 11 residues from the first cysteine (see Figs. 2 and 3 ). The cleavage signal corresponds to that in all other NGFs and also neurotrophins analysed so far, the ( -4 to -1$)$-consensus being $R-X-K / R-R$.
The fish BDNF gene sequence contains an openreading frame of 269 amino acid codons (Fig. 2) presumed to encode the BDNF precursor (deduced molecular mass, $29.7 \mathrm{kDa}$ ). The predicted organization of the fish BDNF precursor strikingly resembles that of the mammalian precursors in size and sequence. The mature fish BDNF which, like its mammalian counterparts, also consists of 119 amino acids (residues 151-269 in Fig. 2), is $90 \%$ identical to that of mouse (Figs. 2 and 3; Table 1). The N-terminal sequence (residues $1-18$ in Fig. 2) serves as a signal peptide and shows a remarkable conservation to the mouse signal sequence ( $89 \%$ identity). The pro-region adjacent to the mature protein has a region of 43 residues with $88 \%$ identity to the mouse protein, the cleavage site (R-V-R-R) of the precursor being identical.

All available sequences were used to calculate the genetic distances for the orthologous gene pairs, corrected for "unobservable" changes according to Dayhoff et al. (1978) and the divergence rates (Table 1). This analysis revealed that the BDNF structure has diverged only very slowly between fish and mammals. In contrast, NGF has evolved at an approximately fivefold higher rate. Later in evolution, the sequence drift for NGF protein has decreased as indicated by

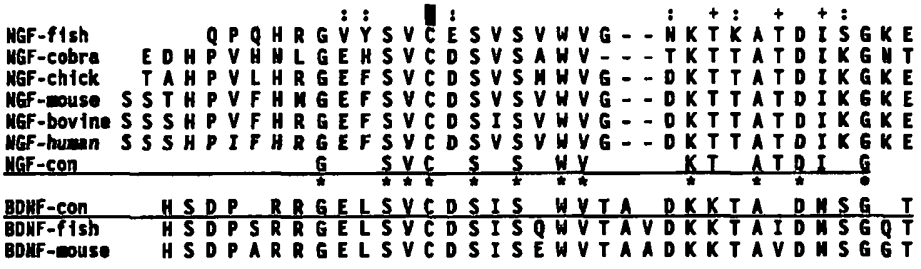

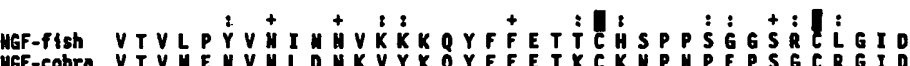

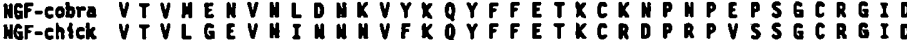

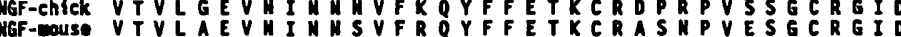

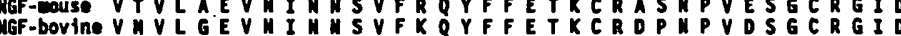

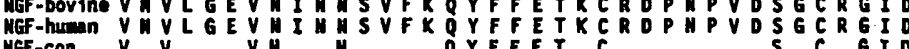

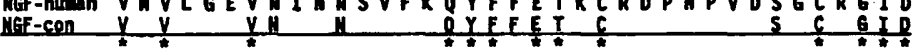
BDUF-con VTV EKYPV GOLKOYFYETKCNPHGYTK GCRGID

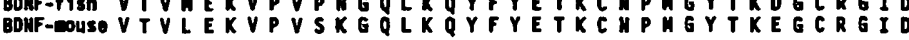

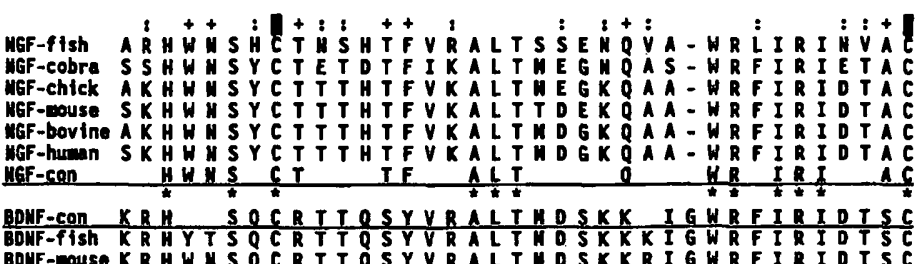
BDMF-mouse KR H W ISOCRTTOSY SRALTHDSKKRIGWRFIRIDTSC
FIG. 3. Evolutionary comparison of neurotrophic factors. The amino acid sequences of fish NGF and BDNF are aligned with those of cobra NGF (Selby et al., 1987b; Oda et al., 1989), chicken NGF (Ebendal et al., 1986; Meier et al., 1986; Wion et al., 1986), bovine NGF (Meier et al., 1986), mouse NGF (Angeletti and Bradshaw, 1971; Scott et al., 1983), human NGF (Ullich et al., 1983), and mouse BDNF (Hofer et al., 1990). Gaps are indicated by dashes to obtain the best homologies. A consensus ("con") for NGF and BDNF is given (underlined); residues identical in all sequences are indicated with an asterisk. The cysteines are marked by squares above the sequence. Residues that are identical in all NGFs but not conserved in BDNF are indicated $(+)$ and residues in fish NGF that differ from the chick/mammals consensus are marked (:). The presumed lengths of the mature neurotrophic proteins are shown at the end of the sequences.

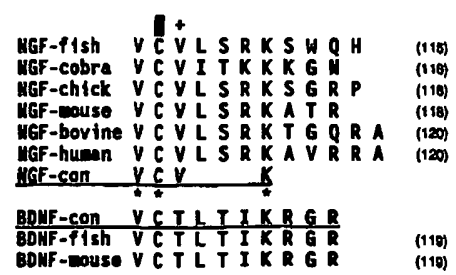


TABLE 1. Conservation of NGF and BDNF protein/gene structures

\begin{tabular}{lccc}
\hline & $\begin{array}{c}\text { Percent } \\
\text { difference }\end{array}$ & PAM $^{a}$ & $\begin{array}{c}\text { Evolutionary } \\
\text { rate }^{b}\end{array}$ \\
\hline BDNF, fish/mouse & $10 / 18$ & $10.7 / 20.5$ & $1.2 / 2.5$ \\
NGF, fish/cobra & $48 / 37$ & $74 / 51$ & $8.2 / 5.7$ \\
NGF, fish/chick & $36 / 33$ & $48 / 43$ & $5.3 / 4.8$ \\
NGF, fish/mouse & $37 / 31$ & $52 / 40$ & $5.8 / 4.4$ \\
NGF, fish/bull & $36 / 32$ & $48 / 41$ & $5.3 / 4.6$ \\
NGF, fish/man & $37 / 33$ & $50 / 43$ & $5.6 / 4.8$ \\
NGF, chick/mouse & $16 / 20$ & $17.9 / 23$ & $3.6 / 4.6$ \\
NGF, chick/bull & $10 / 15$ & $10.7 / 16.5$ & $2.1 / 3.3$ \\
NGF, chick/man & $12 / 17$ & $13.0 / 19$ & $2.6 / 3.8$ \\
\hline
\end{tabular}

${ }^{-}$Evolutionary distance in amino acid PAMs and nucleotide PAMs, respectively [accepted point mutations per 100 residues, according to Dayhoff et al. (1978)].

${ }^{6} \mathrm{PAM}$ per 100 million years.

the comparison between chick and mammais (Table 1). The retrograde extrapolation of the genetic distances and evolutionary rates given in Table 1 indicates that NGF and BDNF have arisen from an ancestral gene by a gene duplication event approximately 600 million years ago.

The NGF and BDNF proteins are colinear and show several domains of strictly conserved amino acids predominantly around the cysteine residues (Fig. 3). One deletion of two residues near the N-terminal of NGF and another one near the C-terminus becomes apparent from this comparison. The consensus amino acids of BDNF amount to 107, whereas for NGF, the level of conservation is less pronounced: 71 residues are identical between fish and mouse and 55 are identical in all species.

To obtain additional information of sequence motifs located at the surface of the neurotrophins, their hydrophilicity profiles were determined using the algorithm of Hopp and Woods (Hopp and Woods, 1981). Whereas the plots of fish and mammalian BDNF are very similar, marked differences become apparent when the NGF plots of fish and higher vertebrates are compared (Fig. 4).

\section{Transcriptional analyses of the NGF and BDNF genes}

In northern blots (Fig. 5) the expression of the BDNF gene (size of transcript $1.8 \mathrm{~kb}$ ) was restricted to adult brain; no signal could be detected in RNA from eye or liver of adult fish. No transcript could be detected following reprobing of the same filter with the NGF probe (not shown). A 3.6-kb message specific for NGF was detected during late organogenesis in embryos between 7 and 17 days old [embryonic stages 16-24 according to Tavolga (1949)] but not in younger embryos or in fish after birth; no BDNF transcript could be detected in these developmental stages (not shown).
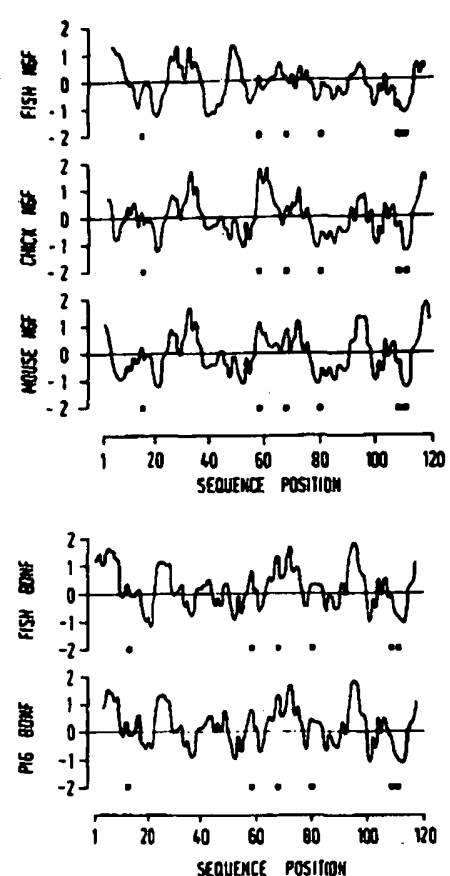

FIG. 4. Comparative hydrophilicity plots of fish and higher vertebrate neurotrophic factors. The average hydrophilicity values (Hopp and Woods, 1981) were calculated over a hexapeptide. The segments of NGF and BDNF predicted to be localized on the (hydrophilic) surface are on the positive end of the $y$-axis. The squares show the position of cysteines.

Expression and purification of fish NGF and BDNF

Because the NGF and BDNF structures have evolved at strikingly different rates we wanted to compare the specific biological activities of the fish pro-

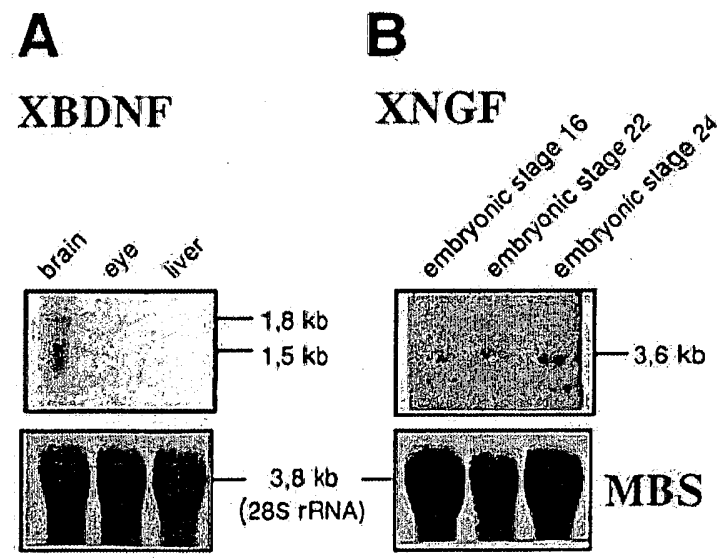

FIG. 5. Expression of (A) BDNF and (B) NGF in Xiphophorus. Northern blot hybridization of total RNA $(20 \mu \mathrm{g})$ isolated from brain, eye, and liver of adult fish or from embryos of the indicated stages; on the right, the transcript sizes are indicated in $\mathbf{~ k b}$. Below, methylene blue stain (MBS) for quantitation of filter-bound RNA. 
FIG. 6. SDS-PAGE of purified fish carried out with reduced samples after HPLC chromatography on an $18 \%$ (wt/vol) polyacrylamide gel and stained with Coomassie Blue. Molecular mass markers are indicated in kilodaltons in lane $M$ and are from top to bottom ovalbumin. carbonic anhydrase, soybean tryp$\sin$ inhibitor, and $\alpha$-lactalbumin. NGF and BDNF. SDS-PAGE was

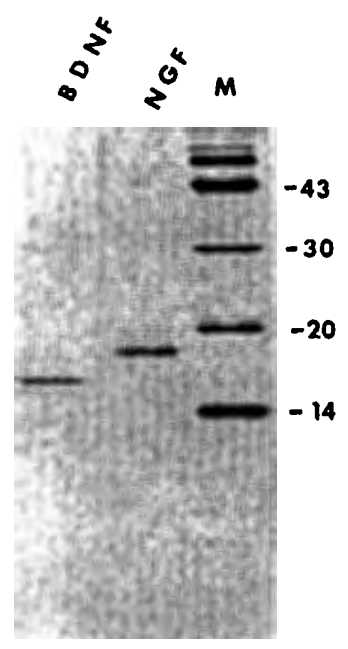

teins to their mammalian homologues. To obtain recombinant fish NGF and BDNF proteins, vaccinia virus expression vectors with the NGF or BDNF genes inserted into their genome were constructed. The conditioned medium harvested from vaccinia virus-infected cells contained at least $200 \mathrm{ng} / \mathrm{ml}$ of recombinant protein $(\sim 1 \%$ of the total protein). The recombinant proteins were purified in a two-step procedure on controlled-pore glass followed by reversedphase HPLC; the SDS-polyacrylamide gel of fish NGF and fish BDNF is shown in Fig. 6. The BDNF preparation showed a single band of $\sim 15 \mathrm{kDa}$ which is close to the value of $13.6 \mathrm{kDa}$ predicted from the DNA sequence; its $\mathrm{N}$-terminal sequence was determined as $\mathrm{NH}_{2}$-H-S-D-P-S. The electrophoretic mobility of recombinant fish NGF was somewhat lower but aminoterminal sequencing yielded the sequence
$\mathrm{NH}_{2}-\mathrm{Q}-\mathrm{P}-\mathrm{Q}-\mathrm{H}-\mathrm{R}$. Thus proteolytic processing had occurred as predicted at the carboxyl side of the sequence motif R-T-R-R (Fig. 2).

\section{Biological activity of fish NGF and BDNF}

The survival effect of $1.5 \mathrm{ng} / \mathrm{ml}$ fish BDNF on chick embryonic sensory neurons was maximal, identical to that obtained with the same concentration of natural (purified from pig brain) or recombinant mammalian BDNF. In contrast, fish NGF at $1.5 \mathrm{ng} /$ $\mathrm{ml}$ showed a detectable but by no means maximal survival effect (Fig. 7). However, when fish NGF was used at $25 \mathrm{ng} / \mathrm{ml}$, the same level of survival was obtained as with maximal concentrations of mouse NGF. Furthermore, the activities of fish NGF and fish BDNF (both added at supramaximal concentrations) were additive, indicating that the factors acted on different subpopulations of neurons. The survival and neurite outgrowth promoting activity of fish NGF on chick sympathetic neurons (which do not respond to BDNF) was similar to the findings on sensory neurons in that a concentration of $\geq 25 \mathrm{ng} / \mathrm{ml}$ was needed to obtain maximal survival values (Fig. 7). Furthermore, fish BDNF but not fish NGF supported the survival of nodose neurons (Fig. 7).

A dose-response curve of the survival of sensory neurons in response to fish NGF and fish BDNF is shown in Fig. 8. Half-maximal effects were obtained with $6 \mathrm{ng} / \mathrm{ml}$ of fish NGF; this specific activity is $\sim 75$-fold lower than that of mouse NGF (Edgar and Thoenen, 1982) or bovine NGF (Harper et al., 1983). Very similar results were obtained with chick sympathetic neurons (data not shown). The biological activity of fish BDNF assayed on sensory dorsal root ganglion neurons (half-maximal survival with $60 \mathrm{pg} / \mathrm{ml}$; Fig. 8) was undistinguishable from that of the mam-

DRG SYMP NOD

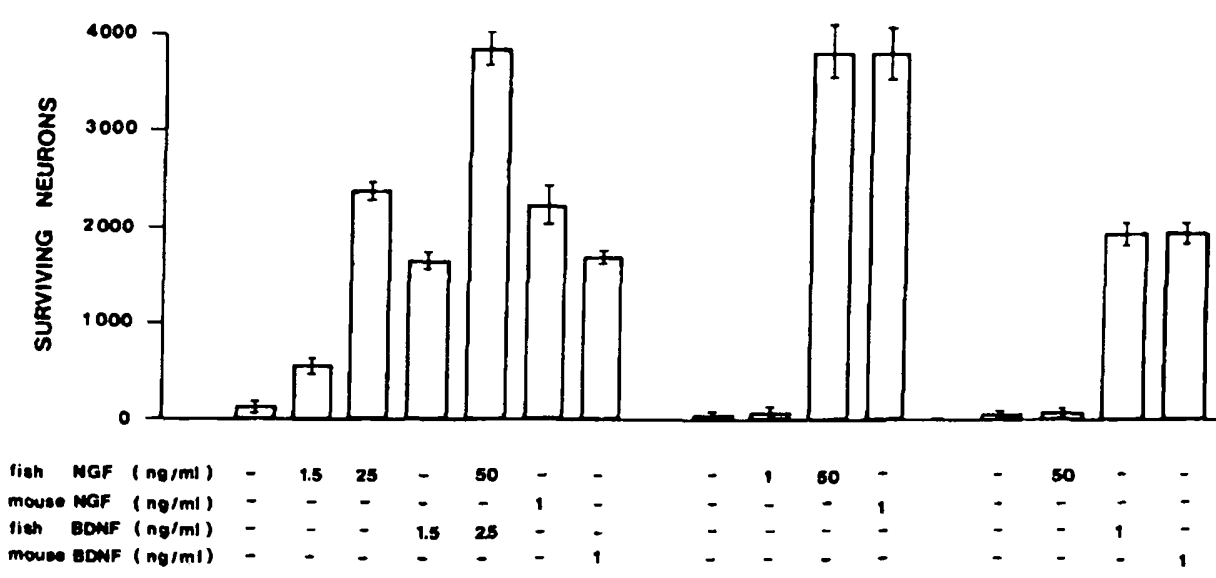

FIG. 7. Specificity of the survival activity of fish NGF and BDNF. Bar charts showing the survival response of sensory neurons prepared from dorsal root ganglia (DRG) of 8-day-old chick embryos (E8), and sympathetic (SYMP, E11) and nodose ganglion (NOD, EB) neurons. Six thousand neurons were plated on laminin/polyornithine substrate and the surviving neurons were counted after 1 day in culture. 


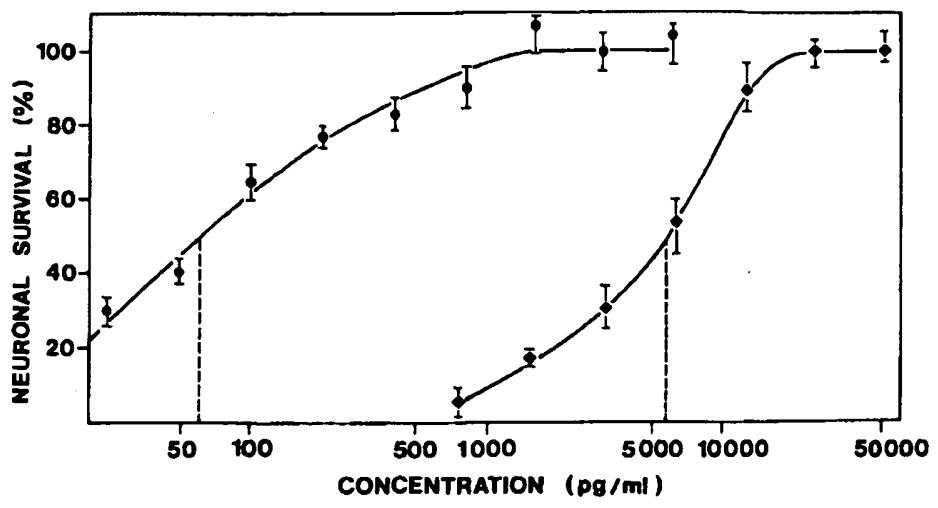

FIG. 8. Dose dependency of the survival activity of fish NGF and fish BDNF. Dose-response curves for the survival of sensory neurons prepared from the dorsal root ganglia of chick in response to fish NGF $(\diamond)$ or fish BDNF (๑), maximal survival being defined as $100 \%$. Six thousand neurons were plated on laminin/polyornithine substrate and the surviving neurons were counted after 1 day in culture. The broken vertical lines show the concentrations of $60 \mathrm{pg} / \mathrm{ml}$ of BDNF and $6 \mathrm{ng} / \mathrm{ml}$ of NGF for half-maximal survival.

malian factor purified from pig brain (RodriguezTébar and Barde, 1988) or produced using recombinant vaccinia virus. The biological activity of fish BDNF assayed on chick sensory neurons (half-maximal at $60 \mathrm{pg} / \mathrm{ml} \approx 2 \times 10^{-12} M$ ) correlates with highaffinity receptors.

\section{DISCUSSION}

\section{Structure-function relationship}

The amino acid sequences of all NGFs and BDNFs analyzed so far, ranging from fish to mammals, are defined by six strictly conserved cysteines (Fig. 3). These cysteines form three intramolecular disulfide bridges whose positions have been determined for mouse NGF (Angeletti and Bradshaw, 1971) and are presumed to be conserved in all other NGF homologs. Besides the 6 cysteines, 34 additional residues are identical in all NGF and BDNF sequences, suggesting that these residues are essential for the correct folding of the molecules, the stabilization of their three-dimensional structure, and the maintenance of their biological activity.

Conversely, there are domains that are different from each other and that determine the different spectra of neuronal specificity of NGF and BDNF (see Barde, 1989; Thoenen, 1991). Fifteen amino acid residues are proposed to belong to this second class (Fig. 3 ), as they are conserved in all NGFs but different in all BDNFs. They are clustered in five or six domains, indicating that several domains (rather than a single one) determine neuronal specificity. Interestingly, the hydropathy plots of NGF and BDNF structures (Fig. 4) differ in these domains due to nonconservative amino acid replacements. This interpretation is strongly supported by a recent study in which the neuronal specificities of NGF-BDNF chimeric molecules were compared and that demonstrated that more than one domain is responsible for the corresponding neuronal specificity (Ibáñez et al., 1991). However, because the chimeric proteins were not purified and the biological activity was determined in a fiber-out- growth assay using ganglion explants, no information on changes in potency of the chimeric proteins was deduced.

The comparison of the sequences of NGFs of higher vertebrates demonstrated that the replacements (which did not result in changes of the specific activity) were generally located in hydrophilic regions (Meier et al., 1986) representing potential immunogenic epitopes and explaining the limited immunological crossreactivity between the different NGFs (Harper et al., 1983). In contrast to the hydropathy plots of BDNF, which are indistinguishable from fish to mammals, the fish NGF plot shows a different profile as compared to higher vertebrates (Fig. 4). Twenty-six residues in fish NGF are different from the chick/mammal NGF consensus (see Fig. 3) and (some) might be responsible for the observed 75-fold lower specific activity of fish NGF on chick sensory and sympathetic neurons as compared to the effects of mouse NGF. Nevertheless, the spectrum of neuronal specificity of fish NGF is preserved. It is noteworthy that several of the changed residues are predicted to be located on the protein surface, e.g., in the regions of the hydrophilic peaks at positions 33 and 47 (Fig. 4). Interestingly, the determination of the crystal structure of mouse NGF revealed that these hydrophilic peaks are surface-exposed $\beta$-hairpin loops (McDonald et al., 1991). According to the more rapid evolutionary changes from fish to bird, the hydropathy plot of snake NGF shows, in comparison to that of higher vertebrates, some differences (not shown) which are also reflected by a low specific activity as determined in the ganglion explant assay (Server et al., 1976).

\section{Evolution of the neurotrophic gene family}

If the evolutionary divergence rates of NGF and BDNF are plotted against a common time scale, the gene duplication event is estimated to have happened approximately 600 million years ago. This is the time when the ancestral vertebrates first appeared in the fossil record. The gene duplication event of the common, probably BDNF-like ancestor is estimated to 
have occurred significantly earlier than the divergence of the fish lineage but later than the divergence of the insects from the phylogenetic tree. The new second copy was then free of selective pressure and might have diverged at an increased rate until it acquired a new but related function. Possible mechanisms leading to this new function might have been replacement of domains by insertion and/or deletion of DNA. This interpretation receives credence by the observation of "missing" residues in NGF as compared to BDNF (Fig. 3).

The extremely low divergence rate on the amino acid level for BDNF is in the range of such highly conserved proteins such as glucagon (evolutionary rate 1.2 from reptiles to mammals). The low divergence rate seems to indicate that BDNF not only fulfills a highly conserved function but also reached an "optimized" structure very early in the vertebrate lineage that tolerated only very little variation. In this context it has to be remembered that the amino acid sequences of all mammalian BDNFs determined so far are identical (Hofer et al., 1990). It is tempting to speculate if the different levels of conservation of NGF and BDNF are also reflected at the level of the corresponding receptors.

\section{Physiological role of NGF and BDNF in fish}

The available data on the expression and biological activity of the two neurotrophic factors in fish do already allow some conclusions with respect to their physiological role. BDNF mRNA was localized unambiguously in brain of adult fish; the levels of NGF mRNA were below the detection limit in all organs investigated. The localization of BDNF mRNA in fish corresponds to that in mammals where BDNF mRNA has been shown to be predominantly expressed in the CNS (Leibrock et al., 1989; Hofer et al., 1990). NGF could be detected only during a limited period of organogenesis (stage 16-24), probably reflecting its role in the formation of the fish sympathetic nervous system that takes place at this developmental time. The effects reported thus far of (mouse) NGF on fish retina neurons are to some extent contradictory. On the one hand, mouse NGF has been reported to stimulate neurite outgrowth from fish retina explants (Turner et al., 1982) and to enhance axonal regeneration following optic nerve crush (Turner et al., 1980; Yip and Grafstein, 1982). However, no evidence could be obtained for the presence of specific NGF receptors on retina ganglion neurons (Yip and Johnson, 1983). In higher vertebrates (rat, chick) no evidence for a survival action of NGF on retina ganglionic cells could be obtained (Johnson et al., 1986; Rodriguez-Tébar et al., 1989).

Acknowledgment: We thank $H$. Thoenen for stimulating discussions and continuous support, Y.-A. Barde for helpful comments and suggestions and for performing the bioassays, F. Lottspeich for protein sequencing, A. Hohn for pro- viding the pig BDNF probe, and R. Kolbeck for help with HPLC purification. R.G. is indebted to H. Stunnenberg and J. Schmitt for the gift of biological materials and help in constructing vaccinia virus recombinants. The excellent technical assistance of Frau Claudia Cap is acknowledged. This work was supported by the Stiftung Volkswagenwerk, Wettbewerb Biowissenschaften (grant to M.S.). R.G. is supported by Regeneron Pharmaceuticals.

\section{REFERENCES}

Adam D., Schartl A., Andexinger S., Hölter S., Wilde B., and Schartl M. (1990) Genetic factors in tumor formation: the melanoma-inducing gene of Xiphophorus. Adv. Mol. Genet. 3, 7994.

Adam D., Măueler W., and Schartl M. (1991) Transcriptional activation of the melanoma inducing Xmrk oncogene in Xiphophorus. Oncogene 6, 73-80.

Angeletti R. H. and Bradshaw R. A. (1971) Nerve growth factor from mouse submaxillary gland: amino acid sequence. Proc. Natl. Acad. Sci. USA 68, 2417-2420.

Barde Y.-A. (1989) Trophic factors and neuronal survival. Neuron 2, 1525-1534

Benton W. D. and Davis R. D. (1977)Screening lambda gt recombinant clones by hybridization to single plaques in situ. Science $196,180-182$

Bradford M. M. (1976) A rapid and sensitive method for the quantitation of microgram quantities of proteins utilizing the principle of protein-dye binding. Anal. Biochem. 72, 248-254.

Cowan W. M., Fawcett J. W., O'Leary D. D. M., and Stanfield B. B. (1984) Regressive events in neurogenesis. Science 225, 12581265.

Dayhoff M. O., Schwartz R. M., and Orcutt B. C. (1978) A model of evolutionary change in proteins, in Atlas of Protein Sequence and Structure, Vol. 5, Suppl. 3 (Dayhoff M. O., ed), pp. 345352. National Biomedical Research Foundation, Washington.

Devereux J., Haeberli P., and Smithies O. (1984) A comprehensive set of sequence analysis programs for the VAX. Nucleic Acids Res. 12, 387-395.

Ebendal T., Larhammar D., and Persson H. (1986) Structure and expression of the chicken $\beta$ nerve growth factor gene. $E M B O J$. $5,1483-1487$

Edgar D. and Thoenen H. (1982) Modulation of NGF-induced survival of chick sympathetic neurons by contact with a conditioned medium factor bound to the culture substrate. Dev. Brain Res. 5, 89-92.

Eichner W., Jäger V., Herbst D., Hauser H., and Hoppe J. (1989) Large-scale preparation of recombinant platelet-derived growth factor AA secreted from recombinant baby hamster kidney cells. Eur. J. Biochem. 185, 135-140.

Ernfors P., Ibánez C. F., Ebendal T., Olson L., and Persson H. (1990) Molecular cloning and neurotrophic activities of a protein with structural similarities to nerve growth factor: developmental and topographical expression in the brain. Proc. Natl. Acad. Sci. USA 87, 5454-5458.

Feinberg A. P. and Vogelstein B. (1983) A technique for radiolabeling DNA restriction endonuclease fragments to high specific activity. Anal. Biochem. 132, 6-13.

Frischauf A.-M., Lehrach H., Poustka A., and Murray N. (1983) Lambda replacement vectors carrying polylinker sequences. $J$. Mol. Biol. 170, 827-842.

Hallbơỏk F., Ibáñez C. F., and Persson H. (1991) Evolutionary studies of the nerve growth factor family reveal a novel member abundantly expressed in Xenopus ovary. Neuron 6, 845-858.

Hannig G., Ottilie S., and Schartl M. (1991) Conservation of structure and expression of the c-yes and fyn genes in lower vertebrates. Oncogene 6, 361-369. 
Harper G. P., Barde Y.-A., Edgar D., Ganten D., Hefti F., Heumann R., Naujoks K. W., Rohrer H., Turner J. E., and Thoenen H. (1983) Biological and immunological properties of the nerve growth factor from bovine seminal plasma: comparison with the properties of mouse nerve growth factor. Neuroscience 8, 375-387.

Heníkoff S. (1984) Unidirectional digestion with exonuclease III creates targeted breakpoints for DNA sequencing. Gene 28 , $351-359$.

Hofer M., Pagliusi S. R., Hohn A., Leibrock J., and Barde Y.-A. (1990) Regional distribution of brain-derived neurotrophic factor mRNA in the adult mouse brain. EMBO J. 9, 24592464.

Hohn A., Leibrock J., Bailey K., and Barde Y.-A. (1990) Identification and characterization of a novel member of the nerve growth factor/brain-derived neurotrophic factor family. $\mathrm{Na}$ ture 344, 339-341.

Hopp T. P. and Woods K. R. (1981) Prediction of protein antigenic determinants from amino acid sequences. Proc. Natl. Acad. Sci. USA 78, 3824-3828.

Huynh T. V., Young R. A., and Davies R. W. (1985) Construction and screening cDNA libraries in lambda gt 10 and $\mathrm{gt} 11$, in DNA Cloning: A Practical Approach, Vol. I (Glover D. M., ed), pp. 49-78. IRL Press, Oxford.

Ibáñez C. F., Ebendal T., and Persson H. (1991) Chimeric molecules with multiple neurotrophic activities reveal structural elements determining the specificities of NGF and BDNF. EMBO J. 10, 2105-2110.

Jacobson M. (1991) Developmental Neurobiology. Plenum Press, New York.

Johnson J. E., Barde Y.-A., Schwab M., and Thoenen H. (1986) Brain-derived neurotrophic factor supports the survival of cultured rat retinal ganglion cells. J. Neurosci. 6, 3031-3038.

Jones K. R. and Reichardt L. F. (1990) Molecular cloning of a human gene that is a member of the nerve growth factor family. Proc. Natl. Acad. Sci. USA 87, 8060-8064.

Kaisho Y., Yoshimura K., and Nakahama K. (1990) Cloning and expression of a cDNA encoding a novel human neurotrophic factor. FEBS Lett. 266, 187-191.

Khandjian E. W. (1986) UV crosslinking of RNA to nylon membrane enhances hybridization signals. Mol. Biol. Rep. 11, 107 115.

Kozak M. (1987) An analysis of 5'-noncoding sequences from 699 vertebrate messenger RNAs. Nucleic Acids Res. 15, 81258148.

Laemmli U. K. (1970) Cleavage of structural proteins during the assembly of the head of bacteriophage T4. Nature 227, 680 685.

Leibrock J., Lottspeich F., Hohn A., Hofer M., Hengerer B., Masiakowski P., Thoenen H., and Barde Y.-A. (1989) Molecular cloning and expression of brain-derived neurotrophic factor. Nature 341, 149-152.

Levi-Montalcini R. (1987) The nerve growth factor 35 years later. Science 237, 1154-1162.

Lindsay R. M., Thoenen H., and Barde Y.-A. (1985) Placode and neural crest-derived sensory neurons are responsive at early developmental stages to brain-derived neurotrophic factor. Dev. Biol. 112, 319-328.

Mackett M., Smith G. L., and Moss B. (1984) General method for production and selection of infectious vaccinia virus recombinants expressing foreign genes. $J$. Virol. 49, 857-864.

Maisonpierre P. C., Belluscio L., Squinto S., Ip N. Y., Furth M. E., Lindsay R. M., and Yancopoulos G. D. (1990) Neurotrophin3: a neurotrophic factor related to NGF and BDNF. Science 247, 1446-1451.

Maniatis T., Fritsch E. F., and Sambrook J. (1982) Molecular Cloning: A Laboratory Manual. Cold Spring Harbor Laboratory, Cold Spring Harbor, New York.

Măueler W., Raulf F., and Schartl M. (1988) Expression of protooncogenes in embryonic, adult, and transformed tissue of $X i$ phophorus (Teleostei: Poeciliidae). Oncogene 2, 421-430.
McDonald N. Q., Lapatto R., Murray-Rust J., Gunning J., Wlodawer A., and Blundell T. L. (1991) New protein fold revealed by a $2.3-\AA$ resolution crystal structure of nerve growth factor. Nature 354, 411-414.

Meier R., Becker-André M., Götz R., Heumann R., Shaw A., and Thoenen $H$. (1986) Molecular cloning of bovine and chick nerve growth factor (NGF): delineation of conserved and unconserved domains and their relationship to the biological activity and antigenicity of NGF. EMBO J. 5, 1489-1493.

Norrander J., Kempe T., and Messing J. (1983) Construction of improved M13 vectors using oligodeoxynucleotide-directed mutagenesis. Gene 26, 101-106.

Oda T., Ohta M., Inoue S., Ikeda K., Furukawa S., and Hayashi K. (1989) Amino acid sequence of nerve growth factor purified from the venom of the formosan cobra Naja naja atra. Biochem. Int. 19, 909-917.

Rhim J. S., Cho H. J., and Huebner R. J. (1975) Non-producer human cells induced by murine sarcoma virus. Int. J. Cancer $15,23-29$.

Rigby P. W. J., Dieckmann M., Rhodes C., and Berg P. (1977) Labeling deoxyribonucleic acid to high specific activity in vitro by nick translation with DNA polymerase I. J. Mol. Biol. 113, $237-251$.

Rodriguez-Tébar A. and Barde Y.-A. (1988) Binding characteristics of brain-derived neurotrophic factor to its receptors on neurons from the chick embryo. J. Neurosci. 8, 3337-3342.

Rodriguez-Tébar A., Jeffrey P. L., Thoenen H., and Barde Y.-A. (1989) The survival of chick retinal ganglion cells in response to brain-derived neurotrophic factor depends on their embryonic age. Dev. Biol. 136, 296-303.

Rosenthal A., Goeddel D. V., Nguyen T., Lewis M., Shih A., Laramee G. R., Nikolics K., and Winslow J. W. (1990) Primary structure and biological activity of a novel human neurotrophic factor. Neuron 4, 767-773.

Saiki R. K., Gelfand D. H., Stoffel S., Scharf S. J., Higuchi R., Horn G. T., Mullis K. B., and Erlich H. A. (1988) Primer-directed enzymatic amplification of DNA with a thermostable DNA polymerase. Science $239,487-491$.

Sanger F., Nicklen S., and Coulson A. R. (1977) DNA sequencing with chain-terminating inhibitors. Proc. Natl. Acad. Sci. USA 74, 5463-5467.

Schwarz M. A., Fisher D., Bradshaw R. A., and Isackson P. J. (1989) Isolation and sequence of a cDNA clone of $\beta$-nerve growth factor from the guinea pig prostate gland. J. Neurochem. 52, 1203-1209.

Scott J., Selby M., Urdea M., Quiroga M., Bell G. I., and Rutter W. J. (1983) Isolation and nucleotide sequence of a cDNA encoding the precursor of mouse nerve growth factor. Nature 302, 538-540.

Selby M. J., Edwards R., Sharp F., and Rutter W. J. (1987a) The mouse nerve growth factor gene: structure and expression. Mol. Cell. Biol. 7, 3057-3064.

Selby M. J., Edwards R. H., and Rutter W. J. (1987b) Cobra nerve growth factor: structure and evolutionary comparison. $J$. Neurosci. Res. 18, 293-298.

Server A. C., Herrup K., Shooter E. M., Hogue-Angeletti R. A., Frazier W. A., and Bradshaw R. A. (1976) Comparison of the nerve growth factor proteins from cobra venom (Naja naja) and mouse submaxillary gland. Biochemistry 15, 35-39.

Southern E. M. (1975) Detection of specific sequences among DNA fragments separated by gel electrophoresis. J. Mol. Biol. 98, 503-517.

Stunnenberg H. G., Lange H., Philipson L., van Miltenburg R. T., and Van der Vliet P. C. (1988) High expression of functional adenovirus DNA polymerase and precursor terminal protein using recombinant vaccinia virus. Nucleic Acids Res. 16, $243 i-2444$.

Sulston J. E. and Horvitz H. R. (1977) Post-embryonic cell lineages of the nematode, Caenorhabditis elegans. Dev. Biol. 56, 110 156.

Tavolga W. N. (1949) Embryonic development of the platyfish 
(Platypoecilus), the swordtail (Xiphophorus), and their hybrids. Bull. Am. Mus. Natl. Hist. 94, 161-230.

Thoenen $H$. (1991) The changing scene of neurotrophic factors. Trends Neurosci. 14, 165-170.

Thoenen H., Bandtlow C., and Heumann R. (1987) The physiological function of nerve growth factor in the central nervous system: comparison with the periphery. Rev. Physiol. Biochem. Pharmacol. 109, 145-178.

Truman J. W. and Schwartz L. M. (1982) Programmed death in the nervous system of a moth. Trends Neurosci. 5, 270-273.

Turner J. E., Delaney R. K., and Johnson J. E. (1980) Retinal ganglion cell response to nerve growth factor in the regenerating and intact visual system of the goldfish (Carassius auratus). Brain Res. 197, 319-330.

Turner J. E., Schwab M., and Thoenen H. (1982) Nerve growth factor stimulates neurite outgrowth from goldfish retinal explants: the influence of a prior lesion. Dev. Brain Res. 4, 59-66.

Ullrich A., Gray A., Berman C., and Dull T. J. (1983) Human $\beta$-nerve growth factor gene sequence highly homologous to that of mouse. Nature 303, 821-825.

Vogelstein B. and Gillespie D. (1979) Preparative and analytical purification of DNA from agarose. Proc. Natl. Acad. Sci. USA 76, 615-619.

Von Heijne G. (1986) A new method for predicting signal sequence cleavage sites. Nucleic Acids Res. 14, 4683-4690.

Whittemore S. R. and Seiger $\AA$. (1987) The expression, localization and functional significance of $\beta$-nerve growth factor in the central nervous system. Brain Res. Rev. 12, 439-464.

Wion D., Perret C., Frechin N., Keller A., Behar G., Brachet P., and Auffray C. (1986) Molecular cloning of the avian $\beta$ nerve growth factor gene: transcription in brain. FEBS Lett. 203, 82-86.

Yip H. K. and Grafstein B. (1982) Effect of nerve growth factor on regeneration of goldfish optic axons. Brain Res. 238, 329-339.

Yip H. K. and Johnson E. M. (1983) Retrograde transport of nerve growth factor in lesioned goldfish retinal ganglion cells. $J$. Neurosci. 3, 2172-2182. 